www.mjn.mosuljournals.com

\title{
RELATIONSHIP BETWEEN FAMILY LIFE -STYLE AND NUTRITIONAL STATUS AMONG KINDERGARTEN CHILDREN IN NINEVAH GOVERNORATE
}

Article information

Article history:

Received May 1, 2018

Accepted January 20, 2019

Available online July 4, 2018

$$
\begin{gathered}
\text { DOI: 10.33899/mjn.2018.162884 @2020, College of Nursing, University of Mosul. } \\
\text { Creative Commons Attribution 4.0 International License } \\
\text { https://mjn.mosuljournals.com/article 162884.html }
\end{gathered}
$$

Abstract

A descriptive study was carried out to determine relationship between family life-style and nutritional status among kindergarten children in Nineveh Governorate for the period $25^{\text {th }}$ December/ 2006 to $29^{\text {th }}$ March /2007. The sample of the study consisted of (450) child. The data were collected by using questionnaire and checking the BMI $\left(\mathrm{Wt} / \mathrm{Ht}^{2}\right)$. The result of the study indicated that there are some significant differences between life-style and variables undertaken in the study. There are also highly significant differences between BMI and the variables. Consequently, the study concluded that family life-style reflects obviously on the BMI of the children. The study recommends that parents and families may pay attention to their life-style and make healthy modifications.

\footnotetext{
${ }^{1}$ Assist. Professor Technical Institute of Mosul Nineveh Health Directorate

${ }^{2}$ Master of Science In Nursing
} 


\section{Mosul Journal of Nursing, Vol. 6, No. 2, 2018 ( 74-82 )}

Introduction

The family is the basic unit within which health behavior including health values, health habits, and health risk perceptions are developed, organized, and performed. Families maintain major responsibility for determining what food is purchased and prepared [1]. Inequalities in health, for example between social groups, are partly explained by deference's in life-style and living conditions, and life-style can vary between groups depending on economic circumstances [2]. Good nutrition is essential for achieving and preserving health while helping the body to protect itself from infection. Because good nutrition can contribute to a person's wellbeing at all stages of illness and may equal number was selected from governmental kindergartens inside Mosul city (150 child); they were gathered through:

A. Special dichotomous questionnaire structured by the researchers. It was completed by the children's parents ( Sample of the study).

B. Measuring weight, height and age of the children and compared them with the International Centiles depended by WHO; CDC; 2000 [4].

The researchers exposed the instrument to a committee of specialized experts in prolong life, it is an important part of holistic palliative care [3]. The study aims to find out the relationship between family life-style and the nutritional status among kindergarten children in Nineveh Governorate.

Methodology

Descriptive design was carried out through the period from 25th December 2006 to 29th March 2007. All private kindergarten children inside Mosul city (150 child) were purposively included in the study. Equal number of kindergarten children was selected randomly by stratified technique (Number) from kindergartens outside Mosul city (150 child), and another

different related fields to ensure the validity of the observational tool, and for testing the reliability of the checklist through it's internal consistency ten children were involved in a pilot study from Al-Fardouse kindergarten, and by Cronbach Coefficient Correlation to compute the reliability, it was $\mathrm{r}=(0.861)$. Number, Frequency, Mean, Standard Deviation, Analysis of Variance (ANOVA), Fisher Freeman Halton Test and Z-test were used to analyze the data.

Results

Table (1) Socio-demographic characteristics of the studied sample. 
Mosul Journal of Nursing, Vol. 6, No. 2, 2018 ( $74-82$ )

\begin{tabular}{|c|c|c|c|c|c|c|}
\hline \multirow{3}{*}{ Variables } & \multicolumn{4}{|c|}{ Urban } & \multirow{2}{*}{\multicolumn{2}{|c|}{ Rural }} \\
\hline & \multicolumn{2}{|c|}{ Governmental } & \multicolumn{2}{|c|}{ Private } & & \\
\hline & \multirow[t]{2}{*}{ No. } & \multirow[t]{2}{*}{$\%$} & \multirow[t]{2}{*}{ No. } & \multirow[t]{2}{*}{$\%$} & \multirow[t]{2}{*}{ No. } & \multirow[t]{2}{*}{$\%$} \\
\hline Sex & & & & & & \\
\hline Male & 79 & 52.7 & 93 & 62.0 & 83 & 55.3 \\
\hline Female & 71 & 47.3 & 57 & 38.0 & 67 & 44.7 \\
\hline \multicolumn{7}{|c|}{ Maternal age (year) } \\
\hline $15-25$ & 18 & 12.0 & 15 & 10.0 & 13 & 8.7 \\
\hline $26-35$ & 86 & 57.3 & 87 & 58.0 & 83 & 55.3 \\
\hline $36-45$ & 44 & 29.3 & 46 & 30.7 & 49 & 32.7 \\
\hline $46-55$ & 2 & 1.3 & 2 & 1.3 & 5 & 3.3 \\
\hline \multicolumn{7}{|l|}{ Child order } \\
\hline 1 & 49 & 32.7 & 62 & 41.3 & 31 & 20.7 \\
\hline $2-4$ & 71 & 47.3 & 62 & 41.3 & 66 & 44.0 \\
\hline$>4$ & 30 & 20.0 & 26 & 17.4 & 53 & 35.3 \\
\hline \multicolumn{7}{|c|}{ Later child spacing (year) } \\
\hline$<1$ & 54 & 36.0 & 52 & 34.7 & 49 & 32.7 \\
\hline $1-2$ & 55 & 36.7 & 66 & 44.0 & 67 & 44.7 \\
\hline$>2$ & 41 & 27.3 & 32 & 21.3 & 34 & 22.7 \\
\hline \multicolumn{7}{|c|}{ Socio-economic status } \\
\hline Low & 47 & 31.3 & 28 & 18.7 & 70 & 46.7 \\
\hline Moderate & 66 & 44.0 & 63 & 42.0 & 68 & 45.3 \\
\hline High & 37 & 24.7 & 59 & 39.3 & 12 & 8.0 \\
\hline
\end{tabular}

The table (1) shows that the percentage of males is higher than females in all types of kindergartens. Maternal ages ranged between $15-55$ years with a highest percentage in the children with mother ages of 26-35 years in the three types of kindergarten. Child order of 2-4 represents the highest percentage in the governmental urban and rural kindergartens. Additionally, the children of 1-2 year latter brother spacing constituted the highest percentage in the three types of kindergartens. For socioeconomic status, the highest percentage of children in the urban kindergarten has moderate status, while the low socioeconomic is the highest in rural kindergartens.

Table (2) Relationship between sex and life-style parameters

\begin{tabular}{|c|ccccc}
\hline Sex & \multicolumn{4}{|c}{ Male $(\mathrm{n}=255)$} & \multicolumn{2}{c}{ Female $(\mathrm{n}=195)$} & \multirow{2}{*}{ p-value } \\
\cline { 2 - 5 } Parameters & Mean & SD & Mean & SD & \\
Child feed & 19.63 & 2.65 & 19.82 & 2.38 & $0.574(\mathrm{NS})$ \\
Disease symptoms & 13.52 & 1.69 & 13.41 & 1.89 & 0.408 (NS) \\
Child activity & 7.43 & 1.49 & 7.08 & 1.42 & 0.010 \\
Child cleanness & 8.22 & 1.50 & 8.45 & 1.54 & 0.044
\end{tabular}

NS $=$ Not significant, according to Z-test

$\mathrm{df}=448 \quad \mathrm{Z}=1.96$

Table (2) shows significant relationship between child sex and each of activity and cleanness at $p=0.01$ and $p<0.05$, respectively. 
Table (3) Relationship between maternal age and life-style parameters

\begin{tabular}{|c|c|c|c|c|c|c|c|c|c|}
\hline \multirow{2}{*}{ Maternal age (yr) } & \multicolumn{2}{|c|}{$15-25(n=46)$} & \multicolumn{2}{|c|}{$26-35(n=256)$} & \multicolumn{2}{|c|}{$36-45(n=139)$} & \multicolumn{2}{|c|}{$46-55(n=9)$} & \multirow[b]{2}{*}{$\mathrm{p}$-value } \\
\hline & Mean & $\mathrm{SD}$ & Mean & $\mathrm{SD}$ & Mean & $\mathrm{SD}$ & Mean & SD & \\
\hline Parameters & & & & & & & & & \\
\hline Child feed & 20.30 & 2.78 & 19.63 & 2.46 & 19.71 & 2.59 & 19.22 & 2.64 & 0.372 (NS) \\
\hline Disease symptoms & 13.54 & 1.81 & 13.52 & 1.65 & 13.37 & 2.00 & 13.11 & 1.76 & 0.769 (NS) \\
\hline Child activity & 7.39 & 1.50 & 7.26 & 1.52 & 7.30 & 1.35 & 7.00 & 1.66 & $0.878(\mathrm{NS})$ \\
\hline Child cleanness & 8.80 & 1.22 & 8.32 & 1.49 & 8.12 & 1.64 & 8.78 & 1.56 & 0.046 \\
\hline
\end{tabular}

NS $=$ Not significant, according to ANOVA test

For the relationship between maternal age and life style parameters, table (3) shows non-significant relationships except with child cleanness at $\mathrm{p}<0.05$.

Table (4) Relationship between child order and life-style parameters

\begin{tabular}{|c|c|c|c|c|c|c|c|}
\hline Child order & \multicolumn{2}{|c|}{$1(n=142)$} & \multicolumn{2}{|c|}{$2-4(n=199)$} & \multicolumn{2}{|c|}{$>4(n=109)$} & \multirow[b]{2}{*}{ p-value } \\
\hline & Mean & $\mathrm{SD}$ & Mean & $\mathrm{SD}$ & Mean & $\mathrm{SD}$ & \\
\hline Child feed & 19.59 & 2.69 & 20.04 & 2.4 & 19.28 & 2.52 & 0.032 \\
\hline Disease symptoms & 13.1 & 2.1 & 13.65 & 1.49 & 13.61 & 1.76 & 0.011 \\
\hline Child activity & 7.25 & 1.58 & 7.33 & 1.45 & 7.23 & 1.37 & 0.799 (NS) \\
\hline Child cleanness & 8.45 & 1.4 & 8.30 & 1.56 & 8.18 & 1.61 & $0.375(\mathrm{NS})$ \\
\hline
\end{tabular}

Table (4) shows significant relationship between child order and each of feed and disease symptoms at $\mathrm{p}<0.05$ and $\mathrm{p}<0.01$ respectively.

Table (5) Relationship between later child spacing and life-style parameters.

\begin{tabular}{c|ccccccc}
\hline Child spacing & \multicolumn{6}{c}{$<1(\mathrm{n}=155)$} & \multicolumn{2}{c}{$1-2(\mathrm{n}=188)$} & \multicolumn{2}{c}{$>(\mathrm{n}=107)$} & \multirow{2}{*}{-value } \\
\cline { 2 - 7 } Parameters & Mean & SD & Mean & SD & Mean & SD & \\
Child feed & 19.86 & 2.7 & 19.72 & 2.37 & 19.49 & 2.59 & $0.506(\mathrm{NS})$ \\
Disease symptoms & 13.43 & 1.94 & 13.45 & 1.78 & 13.55 & 1.54 & $0.856(\mathrm{NS})$ \\
Child activity & 7.48 & 1.47 & 7.3 & 1.5 & 6.96 & 1.36 & 0.020 \\
Child cleanness & 8.03 & 1.51 & 8.36 & 1.63 & 8.66 & 1.27 & 0.004
\end{tabular}

NS = Not significant, according to ANOVA test

The effect of spacing with the later child, has significant effect on child activity and child cleanness at $\mathrm{p}<0.05$ and $\mathrm{p}<0.01$ respectively (table 5).

Table (6) Relationship between socio-economic level and life-style parameters.

\begin{tabular}{l|llll} 
Socio-economic & Low $(\mathrm{n}=145)$ & Moderate $(\mathrm{n}=197)$ & High $(\mathrm{n}=108)$ & $\mathrm{p}$-value \\
\hline
\end{tabular}


Mosul Journal of Nursing, Vol. 6, No. 2, 2018 ( 74-82 )

\begin{tabular}{c|ccccccc}
\hline Parameters & Mean & SD & Mean & SD & Mean & SD & \\
Child feed & 19.19 & 2.63 & 19.87 & 2.51 & 20.12 & 2.38 & 0.008 \\
Disease symptoms & 13.22 & 2.12 & 13.46 & 1.76 & 13.82 & 1.17 & 0.028 \\
Child activity & 6.90 & 1.48 & 7.44 & 1.47 & 7.51 & 1.35 & 0.001 \\
Child cleanness & 8.30 & 1.63 & 8.59 & 1.42 & 7.85 & 1.46 & 0.001
\end{tabular}

NS $=$ Not significant, according to ANOVA test

Table (6) shows significant relationship between socio-economic levels and all studied life style parameters at $\mathrm{p}<0.01$ for feed, $\mathrm{p}<0.05$ for disease symptoms, $\mathrm{p}=0.001$ for child activity and $\mathrm{p}=0.001$ for child cleanness.

Table (7) Relationship between BMI and selected variables.

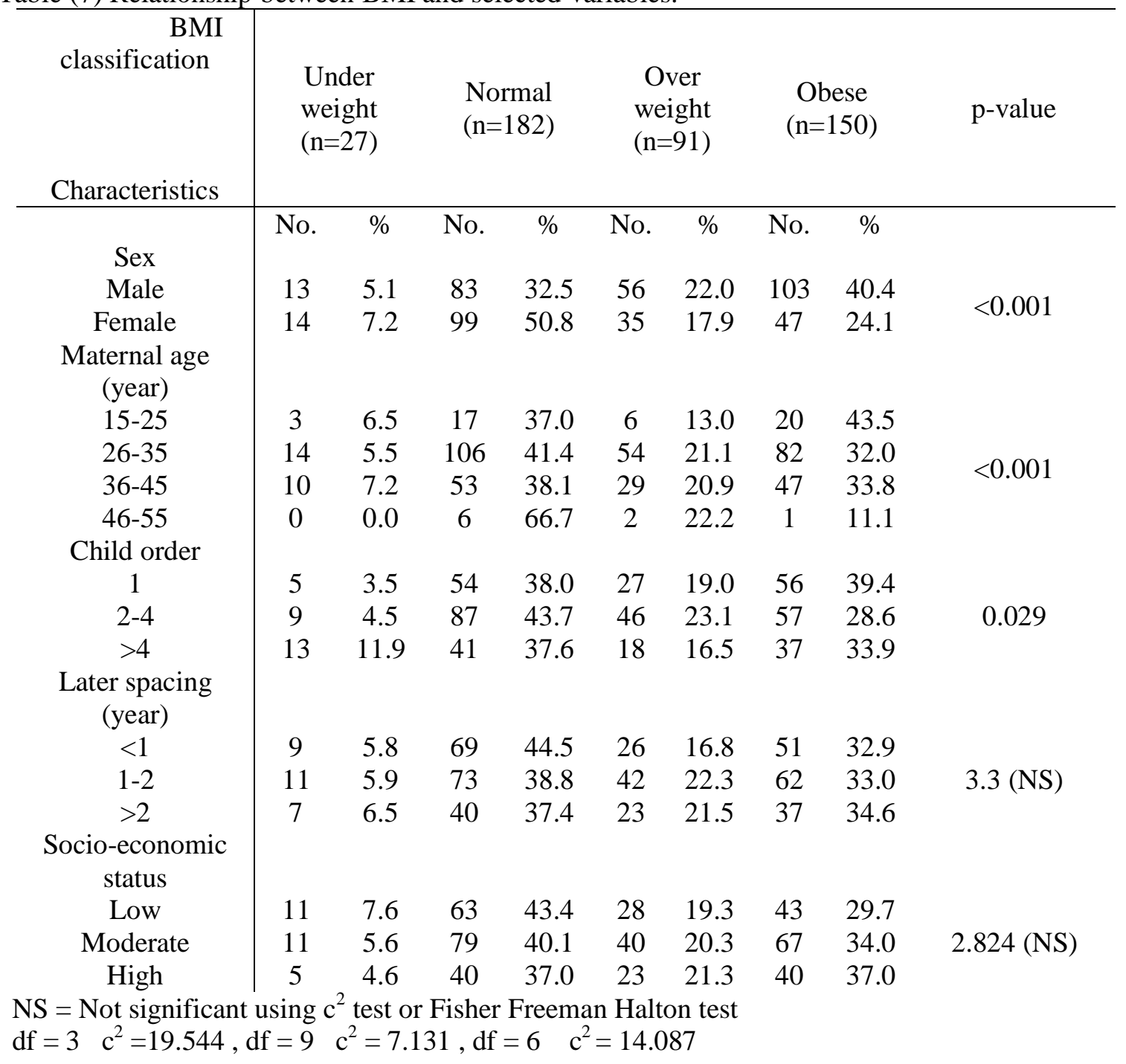

Table (7) shows the relationships between BMI and many selected variables for the children and mothers. A significant relationship was recorded among BMI categories and many variables at different significancy level "Sex at $p<0.001$; Maternal age at $p<0.001 \&$ Child order at $\mathrm{p}<0.05$ ", while the other variables hadn't any significant relation-ship " Later spacing and Socio-economic status". 


\section{Mosul Journal of Nursing, Vol. 6, No. 2, 2018 ( 74-82 )}

Table (8) Relationship between child age and life-style parameters according to kindergarten type.

\begin{tabular}{|c|c|c|c|c|c|c|c|c|c|}
\hline Child age (year) & \multicolumn{2}{|c|}{$4-4.5(n=148)$} & \multicolumn{2}{|c|}{$4.6-5(n=122)$} & \multicolumn{2}{|c|}{$5.1-5.6(n=122)$} & \multicolumn{2}{|c|}{$5.7-6(n=58)$} & \multirow[b]{2}{*}{ p-value } \\
\hline & Mean & $\mathrm{SD}$ & Mean & $\mathrm{SD}$ & Mean & SD & Mean & $\mathrm{SD}$ & \\
\hline Child feed & 19.96 & 2.64 & 19.49 & 2.59 & 19.66 & 2.31 & 19.66 & 2.63 & $0.496(\mathrm{NS})$ \\
\hline Disease symptoms & 13.91 & 1.39 & 13.34 & 1.93 & 13.25 & 2.01 & 13.07 & 1.64 & 0.002 \\
\hline Child activity & 7.05 & 1.4 & 7.16 & 1.54 & 7.46 & 1.43 & 7.74 & 1.45 & 0.007 \\
\hline Child cleanness & 8.27 & 1.47 & 8.19 & 1.63 & 8.44 & 1.6 & 8.45 & 1.25 & $0.52(\mathrm{NS})$ \\
\hline
\end{tabular}

NS $=$ Not significant, according to ANOVA test

For the age of children in the kindergarten, table (3) shows significant relationship at $\mathrm{p}<0.01$ between child age and each of disease symptoms and child activity, while the relationship with feed and child cleanness were not significant.

Table (9) Relationship between weight at birth and life-style parameters according to kindergarten type.

\begin{tabular}{|c|c|c|c|c|c|c|c|}
\hline Wt. at birth $(\mathrm{kg})$ & \multicolumn{2}{|c|}{$<2.5(\mathrm{n}=62)$} & \multicolumn{2}{|c|}{$2.5-3.5(n=329)$} & \multicolumn{2}{|c|}{$>3.5(\mathrm{n}=59)$} & \multirow[b]{2}{*}{ p-value } \\
\hline & Mean & $\mathrm{SD}$ & Mean & $\mathrm{SD}$ & Mean & $\mathrm{SD}$ & \\
\hline Child feed & 19.45 & 2.53 & 19.72 & 2.52 & 19.95 & 2.68 & 0.558 (NS) \\
\hline Disease symptoms & 13.9 & 1.61 & 13.48 & 1.81 & 12.93 & 1.67 & 0.010 \\
\hline Child activity & 7.03 & 1.28 & 7.24 & 1.51 & 7.76 & 1.34 & 0.015 \\
\hline Child cleanness & 8.39 & 1.66 & 8.32 & 1.48 & 8.24 & 1.61 & $0.864(\mathrm{NS})$ \\
\hline
\end{tabular}

NS $=$ Not significant, according to ANOVA test

Weight at birth of the children in the studied kindergarten has significant relationship with disease symptoms and child activity at $\mathrm{p}=0.01$ and $\mathrm{p}<0.05$, respectively (table 7 ). On the other hand, the relationships with feed and child cleanness was not significant ( $p>0.05)$.

Discussion

Many variables (child sex, maternal age, child order in the family, child spacing, eight, socio-economic status) investigated universally with life-style and also with the child BMI, while the socio-economic status variable itself composed of interrelated or overlapping variables, Occupation of father and of mother, Level of education for father and mother, Crowding index, Property [4], which consider mainly the cornerstone variable in any family life-style. The demographic characteristics of the study sample are demonstrated in Table (1).

The life-style in the study is categorized into four domains "child nutrition since birth till nowadays, child activity, presence or absence of such illnesses symptoms, and some cleanness. Significance differences are identified in the life-style domains in relation with variables as: Sex as activity (p. $=0.01)$ and cleanness (p.<0.05)- Table (1); Maternal age as cleanness ( $\mathrm{p} .=0.05)$ - Table (3); Child order as feeding (p.<0.05) and disease symptoms ( $\mathrm{p}=0.01)$ - Table (4); Child spacing as activity (p.<0.05) and cleanness (p.<0.005)- Table (5); Socio-economic status as all domains (feeding, p. $<0.001$ disease symptoms, p. $<0.05$; activity, $\mathrm{p} .=$ 0.001 and cleanness, $p .=0.001$ ); Table (6). 


\section{Mosul Journal of Nursing, Vol. 6, No. 2, 2018 ( 74-82 )}

Growth is generally steady and slow during the preschool and school-age years, but it can be erratic in individual children, with periods of no growth followed by growth spurts. Periods of slow growth and poor appetite can cause anxiety and such disease symptoms, leading to meal time struggles [27].

A balanced diet gives children the nutrition necessary for optimal growth and development and the energy for the exploration they want to do. Through eating right and playing a lot, preschoolers can maintain a healthy weight and stay energized as they get ready for the next big step in their young lives: kindergarten [21].

Proper nutrition and opportunities to play and be physically active are critical to ensure that the child grows properly and adopts healthy behaviors for lifelong health[24].

The position of a child in the family, whether a first born child, a middle child, the (baby) only child, or a one within a large family, will have some bearing on his or her growth and development [23].

Interventions that promote healthy eating and physical activity behaviors during childhood may not only prevent some of the leading causes of illness and death but also decrease direct health care costs and improve quality of life [28].

The problems obviously vary according to age and include breast feeding, weaning, nutrition in the following months and years with changes in life and feeding habits relating to its frequency, or lack of, in the home and then kindergarten [25].

Physical activity is an essential component of any strategy that aims to seriously address the problems of sedentary living and obesity among children and adults [26].

Poor diet and physical inactivity are major contributors to obesity, and the early childhood years are an important period for developing healthy food preferences and motor skills [22].

This can be perhaps due to many reasons; Less perception and awareness of this age, High activity such as in rural residence and sedentary life in urban residence, Disunion between males and females in nurturing, care, also nutrition as our customs and tradition imposed, Deficient knowledge and unqualified practices due to many mothers are of early motherhood expertise, also fatigue of the others of advanced age, Higher child order among family children, Less child spacing period, Abnormal birth weight of the child; decreasing or increasing, and Deviation of many families from the mediate level of socioeconomic status; low or high.

These factors anywhere present they can had a tremendous consequences on the family and on child especially which can be later reflected on his behavior, health, care, follow-up and. A time of heightened vulnerability when disease patterns, interacting with inadequacies of care, can seriously undermine that foundation, often resulting in compromised growth and development, and even death, also Physical activity is an essential component of any strategy that aims to seriously address the problems of sedentary living and obesity among children and adults [5]. In adults, Body Mass Index "BMI" is widely, used as a measure of normal weight (BMI $<25 \mathrm{~kg} / \mathrm{m}^{2}$ ), overweight $\left(\mathrm{BMI}=25-30 \mathrm{~kg} / \mathrm{m}^{2}\right)$ and obesity (BMI $\geq$ $\left.30 \mathrm{~kg} / \mathrm{m}^{2}\right)$ [6].

In children, BMI changes substantially with age, and it is shown that at birth the median BMI is around $13 \mathrm{~kg} / \mathrm{m}^{2}$, at age of one year it is $17 \mathrm{~kg} / \mathrm{m}^{2}$ and it decreases to $15.5 \mathrm{~kg} / \mathrm{m}^{2}$ at age 6 yrs., and then increased to $21 \mathrm{~kg} / \mathrm{m}^{2}$ at age $20 \mathrm{yrs}$ [7].

The problems obviously vary according to age and include breast feeding, weaning, nutrition in the following months and years with changes in life and feeding habits relating to its frequency, or lack of, in the home and then kindergarten [8].

Grima and Genebo (2002) founds that children's nutritional status is also more sensitive to factors such as feeding, weaning, practices, care and exposure to infection at specific ages. Accumulative indicator of growth retardation (Heightfor-Age) in children is positively associated with age [29].

Local and regional studies in Ethiopia have also shown an increase in malnutrition with increase in age of the child [30]. 


\section{Mosul Journal of Nursing, Vol. 6, No. 2, 2018 ( 74-82 )}

Middle childhood is a time of increased mobility and independence for children. It is during this stage that children are taught and expected to behave according to customary gender roles [31].

Mei and others, (1998) said that the prevalence of overweight is higher for girls compared with boys. Also, they observed a parallel increase in the prevalence of overweight between boys and girls among the low-income preschoolers, whereas data from NHANES showed a greater, increase for girls (2.8 percentage point at 2 to 3 years, and 5.0 percentage point at 4 to 5 years than for boys, 1.0 percentage point decrease at 2 to 3 years and only a 0.6 percentage point increase at 4 to 5 years) [9]. Such studies found that time spent outdoors resulted in higher activity also the males are more active than females [10]. Table (7) shows that there is assignificant differences at (P.<0.001) among Body Mass Index and Sex of the children.

The care of the child is the responsibility mainly of the mother, so the mother at it's early motherhood has less knowledge, poor practices of caring, nurturing, feeding and preventing of her child from harms, on the other hand mothers at later age or advanced motherhood period are less able to care and follow their children. Table (7) shows that there is assignificant differences at $(\mathrm{P} .<0.001)$ among Body Mass Index and Maternal age.

The position of a child in the family, whether a first born child, a middle child, the (baby) only child, or a one within a large family, will have some bearing on his or her growth and development [11]. Recent studies have started to indicate adverse effects on later childhood development in large families, especially where socio-economic conditions were especially adverse [12,13]. Birth ordinal is that parents give less attention to order children when they give birth to a new child who needs much attention and care [14]. Jeyasselan (1997) said that higher birth order $(5+)$ is positively associated with child malnutrition [15]. Table (7) shows that there is assignificant differences at $(\mathrm{P} .<0.05)$ among Body Mass Index and child order in the family.
Mozumder et. al.,(2000) indicated the potential importance of longer birth intervals in reducing malnutrition in children, also showed that the proportion of children who were under-weight-forage decreased with the increase in the length of the subsequent birth interval [16]. Girma and Genebo,(2002) said that higher birth spacing is also likely to improve child nutrition, since the mother gets enough time for proper child care and feeding. Studies in developing countries showed that children born after a short birth interval (less than 24 months) have higher levels of stunting in most countries. Preceding birth is also another important demographic variable affecting nutritional status of children. The significant and higher risk of stunting among children of lower preceding birth interval could be due to uninterrupted pregnancy and breast feeding, since this drains women nutritional resources. Close spacing may also have a health effect on the pervious child, who may be prematurely weaned if the mother becomes pregnant again too early [17]. Table (7) shows that there is no a significant differences among Body Mass Index and Later spacing of the child.

Socio-economic status (SES) is determined by age, sex, education, occupation and related social position and income, marital status and living conditions. Health status declines with each decline in SES. According to most literature sources life-style and risk behavior have a close relationship to SES. Life-style is determined by leisure time activities, social contacts. Some studies indicate that healthy life-style is determined by educational level, social position and culture values of the childhood family, rather than being viewed in more individualistic terms in relation to behavioral patterns [18]. It is found that women's educational level and status within the household affects the nutritional status of children. Both adults and children from lower economic groups are found to be less physically active than those of a higher socio-economic status [19]. Socio-economic conditions and lifestyle factors have been found to be related to health, which are an established 


\section{Mosul Journal of Nursing, Vol. 6, No. 2, 2018 ( 74-82 )}

predictor of morbidity and mortality [13]. In most countries, lower socio-economic groups have a significant lower prevalence compared to the middle and high socioeconomic groups as well as environmental and other factors which seem to play a considerable influencing role [20]. Table (9) shows that there is no a significant differences among Body Mass Index and Socio-Economic Status of the family.

\section{Conclusions}

On the basis of the objectives of the present study and the results of data analysis, the following conclusions have been inferred; Most of the life-style domains have significant relation with the variables undertaken in the study; Effect of family life-style is reflected obviously on the BMI of the children; Obese is a nutritional problem among this age period; Significant differences were identified in relation between BMI of the whole children and many variables ( child age, maternal age, birth weight and child order in the family).

Recommendations

According to the results in the study, the researcher puts forward the following recommendations, Enhance family lifestyle and healthy modification may be consolidated financially and socially; The families may plan their parity; Child spacing may be increased at least for 2 years and more; Socio-economic status of the families may be enhance; In-depth researches regarding the nutritional problems especially obesity among preschooler children may be carried out.

\section{References}

Al-Isa, N.; and Moussa, A., 1999: Factors associated with overweight and obesity among Kuwaiti kindergarten children aged 3-5 years, Nutrition Health, 13: PP. (39),(125).

Balia, S.; and Andrew, M., 2005: Mortality, life-style and socio-economic status, University of York, UK, HEDG.

Center Disease of Control and Prevention (CDC), 2000: CDC growth charts, United States, USA.
Center Disease of Control and Prevention (CDC),1996: Physical activity and health: Report.

El-Hazmi, F., 2002: The prevalence of obesity and overweight in 1-18 year old Saudi children, Saudi Arabia, Annals of Saudi Medicine, P. 303.

Escobar, A., 1999: Factors influencing children's dietary practices, Family Economic and Nutrition Review, 12(2,4), PP. 45-55.

Farrier, A.; Harrison, C.; and Oroz, B., 2003: Healthy start for life: promoting healthy eating and life style during the toddler and preschool years, Canadian Institute of Child Health, PP. 1-33.

Grima,W.; and Genebo, T., 2002: Determinant of nutritional status of women and children in Ethiopia, Addis Ababa, Ethiopia, Maryland, USA, PP. 1-5.

Grima,W.; and Genebo, T., 2002: Determinant of nutritional status of women and children in Ethiopia, Addis Ababa, Ethiopia, Maryland, USA, PP. 1-5.

Gwyther, L.; Finch, L.; and Garagango, E.; Kaur, M.; and Merrimon, A., 2006: A clinical guide to supportive and palliative car HIV/AIDS in Sub-Saharron Africa, Nutrition, Published, P. 269.

Homeier, P., 2005: kids health, parents, food and nutrition general nutrition, strategies for feeding a preschooler, KidsHealth, Nemours Foundation, USA, August 2005.

Jeyaseelan, L., 1997: Risk factors for malnutrition in south India children, Journal of Biosocial Science 1: PP. 93100.

Mahan, K.; and Stump, E., 2004: Food, nutrition and diet therapy, 11th edition, SANDERS, USA, PP. (76-112) (260-269).

Mei, Z.; Scanlon, K.; Grummer-strawn, L.; Freedman, D.; yip, R.; and Trowbridge, F., 1998: Increasing prevalence of overweight among us low-income preschool children: The centers for disease.

Molarius, A.; Berglund, K.; Eriksson, C.; Lambe, M.; Nordstrom, E.; Eriksson, H.; and Feldman, I., 2006: Socioeconomic 


\section{Mosul Journal of Nursing, Vol. 6, No. 2, 2018 ( 74-82 )}

condition, Life Style factors, and-related health among men and women, The European Journal of Public Health, Sweden, Article.

Mozumder, A.; Barkat-E-Khuda, T.; Kane, A.; and Levin, S., 2000: The Effect of Birth Interval on Malnutrition in Bangladeshi Infants and Young Children, Journal Biosocial Sci., 32: PP. 289-300.

Patrick, K.; Spear, B.; Holt, K.; and Sofka, D., 2001: Bright futures in practice:

physical activity, National center for Education in Maternal and Child Health, Arlington, VA.

Phillin, K., 1996: Some implications of early auditory development for the environment of hospitalized pre-term infants, Neonatal Network, 5(8), P.71.

Phillin, K., 1996: Some implications of early auditory development for the environment of hospitalized pre-term infants, Neonatal Network, 5(8), P.71.

Public Health Services (PHS), 2000: National health promotion and disease prevention objectives, Healthy People, USDHHS, Washington, DC,USA.

Serrano, E., 2006: Healthy eating for children two though five years old: A guide for parents and child care providers, Virginia Cooperative Extension, Virginia State University, USA.

Slachtova, H.; Tomaskova, H.; and Splichalova, A., 2003: Socioeconomic predictors of life style, Institute of Public Health, Ostrava, Czech, PP. 1-6.
Sommerfelt, A.; Elizabeth, S.; and Kathryn., M., 1994: Children's nutritional status, DHS Comparative Studies, Macro International Inc., Calverton, Maryland, USA, No. 12.

Strumendo, T., 1997: Problematic in childhood nutrition, Medicina, Leadership Medica, Italian.

Strumendo, T., 1997: Problematic in childhood nutrition, Medicina, Leadership Medica, Italian.

Toohey, J.; Keegan, K.; Morgan, M.; and Francis, J., 1995: Task S and deVeciana M. The 'dangerous multipara' : fact or fiction?, American Journal of Obstetrics and Gynecology, 172 (2 Part 1): PP. 683686.

United Nation Children Emergency Foundation (UNICEF), 2006: Analysis of the situation of children and women in the Democratic people's republic of Korea, UNICEF DPRK, Unite for Children, P. 30.

World Health Organization (WHO), 1995: Physical status: the use and_interpretation of anthropometry, Geneva: WHO.

World Health organization (WHO), 2006: Promoting physical activity and active living in urban environments, Turkey, P.3.

World Health organization (WHO), 2006: Promoting physical activity and active living in urban environments, Turkey, P.3.

Yimer, G., 2000: Malnutrition among children in southern Ethiopia: Levels and risk factors: Ethiopian Journal of Health Development, 14(3), PP.283-292. 